\title{
Progress in study of Cannabis sativa leaves extracts without psychotropic cannabinoids in animal model of neuropathic pain
}

\author{
Marcin Ożarowski ${ }^{1,2}$, Przemysław Ł. Mikolajczak ${ }^{2,3}$, Anna Bogacz 2, 4 , \\ Joanna Bartkowiak-Wieczorek ${ }^{2,4}$, Radosław Kujawski , Marian Majchrzycki ${ }^{5}$, \\ Karolina Wielgus ${ }^{6}$, Agnieszka Seremak-Mrozikiewicz ${ }^{2,7,8}$, Bogusław Czerny, 10 \\ ${ }^{1}$ Department of Pharmaceutical Botany and Plant Biotechnology, Poznan University of Medical Sciences, Poland \\ ${ }^{2}$ Department of Pharmacology and Phytochemistry, Institute of Natural Fibres and Medicinal Plants, Poznan, Poland \\ ${ }^{3}$ Department of Pharmacology, Poznan University of Medical Sciences, Poland \\ ${ }^{4}$ Laboratory of Experimental Pharmacogenetics, Department of Clinical Pharmacy and Biopharmacy, Poznan University \\ of Medical Sciences, Poland \\ ${ }^{5}$ Department of Reumathology and Rehabilitation, Poznan University of Medical Sciences, Poland \\ ${ }^{6}$ Department of Biotechnology, Institute of Natural Fibres and Medicinal Plants, Poznan, Poland \\ ${ }^{7}$ Division of Perinatology and Women's Diseases, Poznan University of Medical Sciences, Poland \\ ${ }^{8}$ Laboratory of Molecular Biology, Poznan University of Medical Sciences, Poland \\ ${ }^{9}$ Department of General Pharmacology and Pharmacoeconomics, Pomeranian Medical University, Szczecin, Poland \\ ${ }^{10}$ Department of Stem Cells and Regenerative Medicine, Institute of Natural Fibres and Medicinal Plants, Poznan, Poland
}

\section{ABSTRACT}

Neuropathic pain is a type of chronic pain caused by a lesion or disease of the somatosensory nervous system. Current therapy for this pain includes the use of pharmacological and nonpharmacological methods but due to the fact that a lot of therapy does not produce the analgesic results, it is necessary to search for new and more effective pharmacological strategy in relief of this type of pain. One of the interesting natural sources of compounds against this type of pain is extract of Cannabis sativa without psychotropic cannabinoids. Medicinal properties of $C$. sativa have been explored for centuries. It is well established that active compounds of this herb act through two cannabinoid receptors (CB1, CB2) as endocannabinoid system in the central nervous system. The present review addresses the recent advances in the study of pharmacological mechanisms on cellular and receptor level underlying non-hallucinogenic cannabinoid analgesic effect. In recent years, results of studies allow to state that special plant extract of $C$. sativa (without psychotropic cannabinoids) may be a promising source of drug used to relieve neuropathic pain.

Keywords: cannabinoids, analgesic effect, animal models.

\section{Introduction}

The International Association for the Study of Pain [1] defines neurophatic pain (NP) as pain initiated or caused by a primary lesion or dysfunction in the nervous system, thus NP may be caused by any disease or injury to the nervous system. A nerve lesion leads to serious changes in the nervous system and makes it distinct NP from other chronic pain types that have an intact nociceptive system [2]. Pain occurring in acute or chronic diseases, including NP, are a very common challenge in medical care. Thus, pharmacotherapy of this pain is one of the top priorities in developed countries. Currently, it is estimated that $7-8 \%$ of the general population in Europe suffer from NP [3], but in 30 to $40 \%$ of patients 
with diabetes have symptoms suggesting neuropathy [1]. Moreover, different type of pain occur in as many as $90 \%$ of patients during cancer [4] and it is predicted that at least $15-20 \%$ of patients may suffer from NP during the course of the cancer [5]. The research issue becomes even more complex and socially urgent due to the fact that the anatomical classification of NP includes over 50 types of diseases associated with the pathogenesis of pain [2], for example phantom pain, trigeminal neuralgia, carcinoma-associated paraneoplastic peripheral neuropathy, acute or inflammatory polyradiculoneuropathy (Guillain-Barre syndrome), diabetic mononeuropathy, alcoholism, amyloidosis, multiple sclerosis, traumatic brain injury, Parkinson's disease, mastectomy. According Gondim et al [6], peripheral neuropathy in inflammatory bowel disease also belongs to NP. In particular, the inflammatory bowel diseases are an increasing challenge for pharmacotherapy, and this is because of contraindications to conventional analgesics. Due to the fact that a lot of therapy does not produce the expected results in the treatment of $N P$, it is necessary to search for new and more effective pharmacological solutions in relief of this type of pain $[2,7]$. This is even more important, due to the fact that opioids and nonsteroidal anti-inflammatory drugs are among the most commonly used drugs in clinical practice, their use subsequently can induce unexpected drug interactions and/or several types of these medicines often produce several adverse reactions [8]. Nowadays, beside typical analgesics, also antidepressants, anticonvulsants [9], capsaicin, and memantine are used in pain relief [1]. In the recent years, the problem becomes even more complex because chemotherapy (e.g. use of such drugs as cisplatin, paclitaxel, vincristine) can also induce sensory neuropathies as an adverse drug effect (neurotoxicity) [10].

\section{Impact of cannabinoid receptors in pain}

A very interesting option in this field may be plant extract from Cannabis sativa L. This is important for NP therapy, because results of many researches showed occurrence of high density cannabinoid receptors (CB1 and (B2) in many areas related to pain (endocannabinoid system, ED) [11, 12]. It was shown that deregulation of the ED underlies several neurological disorders including chronic pain [13]. In human brain two endocannabinoids were found out, $\mathrm{N}$-arachidonoyl ethanolamine (anandamide), the first discovered and best studied endogenous lipid-signaling ligand and 2-arachidonoyl glycerol (2-AG) which acts through cannabinoid receptors [14-16]. It is important to note, that other chemical compounds may belong to endocannabinoids such as dihomo- $\gamma$-linolenoylethanolamide, docosatetraenoylethanolamide, and possibly the CB1-selective agonist - 2-arachidonylglyceryl ether (noladin ether). ${ }^{9} \mathrm{~N}$-arachidonoyl dopamine, $\mathrm{N}$-oleoyl dopamine, and oleamide [17].

Studies have reported a similar distribution of CB1 cannabinoid and mu-opioid receptors in sites which are strongly involved in antinociception as the dorsal horn of the spinal cord [18], the caudate putamen, dorsal hippocampus, substantia nigra $[19,20]$, raphe nuclei, central medial thalamic nuclei and hypothalamus [21, 22]. A growing body of literature attests to the interaction between opioids and cannabinoids at the receptor and signal transduction levels [23]. Another study in animal model showed that cannabinoid receptor agonists increased proenkephalin gene expression in the caudate-putamen, nucleus accumbens, paraventricular and ventromedial hypothalamic nuclei and also medial mamillary nucleus [24]. Moreover, Vigano et al. [23] concluded that $C B 1$ receptors may be necessary for the expression of several effects of opiates, so CB1 antagonists may offer a novel approach for treating opiate addiction and the cannabinoids use may help relieve the effects of opiate withdrawal. Several studies showed, that agonists for CB1 receptor exert an antiinflammatory, anti-nociceptive and anti-hyperalgesic properties in the central and peripheral nervous system levels [25]. It was demonstrated furthermore that activation of peripheral CB2 receptors generates an antinociceptive response in situations of inflammatory hyperalgesia and NP by inhibiting the release of proinflammatory factors in non-neuronal cells located near nociceptive neuron terminals [26]. CB2 receptors are mainly located in the immune system, therefore representing a target in inflammatory pain processing [27]. Recent results of the research provided evidence of the involvement of cannabinoid receptors in the supraspinal modulation of pain in different models with use intra-cerebral microinjections of cannabinoid ligands or positive modulators for CB1 receptors [27]. The study has demonstrated that synaptically released glutamate, as a result of pain, stimulates mGlu5 receptor inducing endocannabinoid release, which in turn activates presynaptic cannabinoid CB1 receptor. Moreover, it was explained that $C B 1$ receptor activation expressed on presynaptic GABAergic terminals reduces the probability of neurotransmitter release thus dis-inhibiting the periaqueductal grey-rostral ventromedial medulladorsal horn (PAG-RVM-DH) antinociceptive pathway. 
According to Palazzo et al. [27], cannabinoids may increase a glutamate release (maybe as consequence of GABA decrease) and require a glutamate receptor activation to induce the antinociception phenomena.

\section{Neuroinflammation and NP}

Very often the NP is disproportionately enhanced in intensity (hyperalgesia) or altered in modality (hyperpathia or allodynia) in relation to the stimuli leading to changes in some factors coupled with inflammation [28]. The inflammatory response initiates a cascade of events inducing the concentration and activation of innate immune cells at the site of tissue injury and as a consequence an infiltration of damaged peripheral nerves by mast cells, granulocytes, macrophages and $T$ lymphocytes which leads to release of immunoactive substances such as cytokines, neurotrophic factors, and chemokines initiating a local actions and can result in a more generalized immune response [29]. Proinflammatory cytokines, eg. interleukin-1beta (IL-1ß) and tumor necrosis factor-alpha (TNF $\alpha$ ) secreted by activated glial cells in the spinal cord and the brain play probably prominent role in inflammation-induced nociception [30]. Recent study showed that a chronic constriction injury led to increase of TNF $\alpha$ level in the sciatic nerve [31]. These proinflammatory cytokines exert their actions, at least partially, through the activation of the transcription factor, nuclear factor kappaB (NFkappaB), which, in turn, regulates the transcription of many inflammatory mediators by binding to the promoter region of various genes, [eg. tumor necrosis factor $\alpha(\mathrm{TNF} \alpha)$, interleukin $1 \alpha(\mathrm{IL} 1 \alpha)$, cyclooxygenase-2 (COX-2), inducible NO-synthase (iNOS) and proteases (eg. matrix metalloproteases (MMPs)) [32-34]. It is well documented that the dysregulation of NF-kB activity is associated with risk of neurodegeneration [35] and with alteration of synaptic plasticity [36, 37]. In dorsal root ganglia and the spinal cord of rats an increased number of activated NF-kB immunoreactive neurons and astrocytes was observed [36, 38]. Several studies indicate that the NF-kB activation pathway plays a crucial role not only in the immune responses, inflammation, and apoptosis but also in the development and processing of pathological pain [39]. The results indicate that NF-kappaB has an impact on nociceptive transmission and processing and that a number of substances that inhibit the NF-kappaB-activating cascade are capable of reducing the nociceptive response in different animal models. Therefore, a modulation of specific participants in the NF-kappaB signal transduction might exert a useful approach for the development of pain release drugs [40]. Both experiments performed in in vivo model [41] and studies done in patients during acute migraine attacks [42] have revealed also the possibility of the NF-kB activation by transcriptional regulation of iNOS. Moreover, results from Wu et al. [43] suggest that reciprocal changes in the expression of ZAS3 (a member of zinc finger protein family) and NF-kappaB proteins might generate NP after peripheral nerve injury [43]. Recent experiments showed that glial NF- $\kappa$ B inhibition reduces galanin and CGRP expression, which are neuropeptides that correlate with pain behavior and inflammation after peripheral nerve injury $[44,45]$.

\section{Other receptor mechanism of NP pathogenesis}

A relationship was demonstrated between the N-Methyl-D-Aspartate receptor (NMDAR)-mediated neuronal excitation and nociceptive behavior. There is considerable evidence that activation of NMDAR contributes to the mechanism of pathological pain, hence a NR2Bcontaining NMDA receptor is one of the best potential targets for NP $[46,47]$. It is in line with information that hypoactivity of the spinal cannabinoid system results in an NMDA-dependent hyperalgesia and thus may participate in the etiology of certain chronic pain conditions [48]. Moreover, previously it was shown that NMDA-antagonists are effective in decreasing autotomy (self-injurious behavior) and relieving neuropathic symptoms in other types of experimental peripheral neuropathies [49], but based on the systematic review of clinical trials, no conclusions can yet be made about the efficacy of NMDA receptor antagonists on NP [50].

\section{Phytochemistry and biological activi- ties of Cannabis sativa extracts}

The Cannabis sativa L. has been known for centuries as a psychoactive plant and they has been used for thousands of years in ethnomedicine to relieve human suffering. The plant produces over 421 chemical compounds, including about 80 terpeno-phenol compounds named phytocannabinoids [51] and these cannabinoids and hemp extracts may exert different and promising pharmacological activities. Several studies have shown that the most important psychoactive compound of cannabis extract is considered to be $\Delta 9$-tetrahydrocannabinol (THC) [52-55]. However, there are also well known phytocannabinoids with very weak or no psychotro- 
pic effects. These include cannabidiol (CBD) [56], cannabigerol (CBG), cannabichromene (CBC), D9-tetrahydrocannabivarin (D9-THCV), cannabidivarin (CBDV), D9-tetrahydrocannabinolic acid (D9-THCA) and cannabidiolic acid (CBDA) [51], and also the main compound of essential oil - beta-caryophyllene [57]. Phytochemical analysis of 11 cannabis varieties proved chemical differences between Cannabis spp. [58]. Many recent studies with use gas chromatography (GC) analyzing cannabinoids and terpenoids have been performed for chemotaxonomic purposes [58]. Chemotaxonomic evaluation of cannabis has led to the recognition of three chemotypes [59]:

1. Chemotype I - narcotic hemp, where delta 9 THC and carboxy THC to CBD and carboxy CBD ratio is much higher than $1(>1)$,

2. Chemotype II - intermediary hemp, where delta 9 THC and carboxy THC to CBD and carboxy CBD ratio is about 1 ,

3. Chemotype III - fibrous hemp, where delta 9 THC and carboxy THC to CBD and carboxy CBD ratio is much lower than $1(<1)$.

In accordance with review of Izzo et al. [51], nonpsychotropic phytocannabinoids exert multiple pharmacological effects and the most recently investigated mechanisms of their biological actions involve the modulation of the endocannabinoid system, transient receptor potential channels, the peroxisome proliferatoractivated receptor GPR55, the putative abnormal-CBD receptor, 5-hydroxytryptamine receptor subtype $1 \mathrm{~A}$, glycine $\mathrm{a} 1$ and $\mathrm{a} 1 \mathrm{~b}$ receptors, the adenosine membrane transporter phospholipase A2, lipoxygenase (LOX) and cyclooxygenase-2 (COX-2) enzymes, and $\mathrm{Ca} 2+$ homeostasis. At present, it was shown that D9-THCV is a CB1 receptor antagonist [60]. It was found out that at low doses ( $<3 \mathrm{mg} / \mathrm{kg}$ ) it antagonises D9-THC effects, but it acts as a CB1 agonist at higher doses (10 mg/ $\mathrm{kg}$ ) in vivo in mice [51]. In the study performed by Bolognini et al. [61] it was shown that D9-THCV can activate CB2 receptors in vitro and decrease signs of inflammation and inflammatory pain in mice partly via CB1 and/or CB2 receptor activation. In mouse models of carrageenan-induced inflammation and inflammatory pain and formalin-induced hyperalgesia, D9-THCV suppressed signs of these pathological processes [61]. In detail, the THCV reduced the formalin-induced pain behaviour when administered at a dose of $5 \mathrm{mg} \cdot \mathrm{kg}^{-1}$ and suppressed carrageenan-induced signs of inflammation and inflammatory pain in mice when it was injected 30 min before carrageenan. This investigation has demonstrated that the anti-edema activity exhibit- ed by THCV appeared to be CB2, but not CB1 receptor mediated, its anti-hyperalgesic activity seemed to be mediated by both CB1 and CB2 receptors in the formalin model, but by neither of these receptors in the carrageenan model. Therefore it means that peripheral antinociception without CNS effects is consistent with the peripheral distribution of $\mathrm{CB} 2$ receptors [62]. Further research directed at identifying the mechanisms underlying these in vivo effects of THCV, is needed.

Results of Gertsch et al. [63] research proved that another non-psychotropic compound, (E)-beta-caryophyllene $[(E)-B C P]$, which is one of the most abundant in the plant essential oil, has been shown to selectively target the $\mathrm{CB} 2$ receptor at $\mathrm{nM}$ concentrations and to act as a full agonist. Moreover, Gertsch et al. [63] demonstrated that (E)-BCP (500 nM) inhibited the lipopolysaccharide (LPS)-induced proinflammatory cytokine expression in peripheral blood and (E)-BCP at $5 \mathrm{mg} \mathrm{kg}^{-1}$ strongly reduced the carrageenan-induced inflammation in mice. These data confirmed that different CB2 receptor-selective ligands, including CB2 receptor agonists, are able to inhibit carrageenan-stimulated edema formation in mice. According to Bento's results [64] it was found also that the (E)-BCP reduced cytokine levels (tumor necrosis factor- $\alpha$, keratinocytederived chemokine, and macrophage-inflammatory protein-2) in a culture of macrophages stimulated with lipopolysaccharide. Klauke et al. [65] confirmed that (E)-BCP exerts its analgesic effects in mouse models of inflammation and NP (formalin-induced inflammation model) and a model of NP, which involves the partial ligation of the sciatic nerve in male wild type $\left(\mathrm{CB2}^{+} /^{+}\right)$and $\mathrm{CB2}{ }^{-} \digamma$ mice). It was observed that analgesic effects of (E)-BCP were absent in $\mathrm{CB}^{-} \digamma$ mice and blocked by the CB2 antagonist SR144528. Moreover, using von Frey test and Hargreaves test they showed, that in mechanical allodynia (E)-BCP exerted a strong effect at a dose $10 \mathrm{mg} / \mathrm{kg}$, but in second test only 1 $\mathrm{mg} / \mathrm{kg}$ gradually reduced thermal hyperalgesia.

Another major psycho-inactive component of cannabis, CBD has been more thoroughly investigated. CBD has exerted analgesic and anti-inflammatory, antioxidant, neuroprotective and pro-apoptotic activities and might predict a possible future use for the treatment not only of pain, but also of neurodegenerative disorders, ischemia and cancer [51]. Additionally, Zuardi et al. [66] showed that the antipsychotic action of CBD was similar to atypical antipsychotics such as clozapine. Moreover, CBD has exerted anxiolytic-like effects by activating post-synaptic 5-HT(1A) receptors in the periaqueductal gray matter [67]. 
However, among published studies the most strong pharmacological effect showed that CBD has substantial anti-nociceptive and anti-inflammatory activities. Previously, Evans et al. [68] and Formukong et al. [69] found that CBD was more effective than other natural cannabinoids in the phenylbenzoquinone (PBQ)induced mouse writhing test. They concluded that the compound was about 360 times more potent than aspirin and 590 times more potent than THC [68, 69]. There are also inconsistent results of studies, for example Sanders et al. [70] showed that orally administered CBD was inactive in the acetic acid stretching model and CBN was only effective at high concentrations. In the study performed by Costa et al. [71] in both neuropathic (sciatic nerve chronic constriction) and inflammatory pain (complete Freund's adjuvant intraplantar injection) in rats' model, it was found that treatment with CBD at dose of $2.5-20 \mathrm{mg} / \mathrm{kg}$ (neuropathic model) and at $20 \mathrm{mg} / \mathrm{kg}$ (adjuvant-injected rats) from day 7 to day 14 after the injury, reduced hyperalgesia to thermal and mechanical stimulation. A reduction was also demonstrated in the content of several mediators, e.g. prostaglandin E2 (PGE2), lipid peroxide and nitric oxide (NO) after CBD treatment. On the basis of these results one may conclude that the CBD exerts the therapeutic potential in NP. Moreover, when CBD was administered orally (5-40 $\mathrm{mg} / \mathrm{kg}$ ) once a day for 3 days after the carrageenaninduced inflammation in the rat, it exerted not only anti-inflammatory effect but also six hours after carrageenan injection, the lower doses of CBD abolished a hyperalgesia [72]. It was calculated that CBD at a dose of $5 \mathrm{mg} / \mathrm{kg}$ reduced edema to $50 \%$, at 7.5, 5 and $10 \mathrm{mg} / \mathrm{kg}$ to about $65 \%$ and to $100 \%$ after 40 $\mathrm{mg} / \mathrm{kg}$. These authors demonstrated also that CBD in the dose of $10 \mathrm{mg} / \mathrm{kg}$ non-significantly reduced COX activity (21\%) and the doses of 20 and $40 \mathrm{mg} / \mathrm{kg}$ of CBD brought COX activity down to the level of non-inflammed tissues. Although there is an increasing number of experimental works and clinical studies explaining the mechanism of extracts obtained from Cannabis sativa, the data defining whether its biologically active compounds influence the expression at mRNA and/or protein level is still insufficient. It was shown for example that oral administration of ajulemic acid (1'-1'-dimethylheptyl-THC-11-oic acid; AjA), a cannabinoid acid devoid of psychoactivity, reduces joint tissue damage in rats with adjuvant arthritis. Zurier et al. [73] in an in vitro study (on peripheral blood and synovial fluid monocytes - PBM and SFM - isolated from healthy subjects and from patients with inflam- matory arthritis, respectively) have revealed that $\mathrm{AjA}$ in doses 0-30 microM did not influence TNF $\alpha$ production by activated cells but AjA reduced levels of IL-1 $\beta$ mRNA in a concentration-dependent manner which might be helpful to explain the therapeutic effects of AjA in the animal model of arthritis [73]. In CBD treated mice a significant reduction of plasma levels of the pro-inflammatory cytokines, IFN-gamma and TNF $\alpha$ was observed [74]. Furthermore, Costa et al. have examined whether CBD inhibited the production of nociceptive and inflammatory mediators involved in development and maintenance of NP and inflammation. In rats orally treated with CBD $(2.5-20 \mathrm{mg} / \mathrm{kg}$ to neuropathic and $20 \mathrm{mg} / \mathrm{kg}$ to adjuvant-injected rats) from day 7 to day 14 after the injury no reduction in NF-kappaB activation and TNFa content was observed [71]. There has been some evidences on the efficacy of analgesic effect of cannabinoids originating not only from different animal models [75], but from clinical trials which included e.g. patients with peripheral neuropathy in inflammatory bowel disease [6], sclerosis multiplex [76] and also in cancer pain [77].

\section{Preparations containing the $C$. sativa extract}

In 2005, Ministry of Health of Canada has approved SATIVEX ${ }^{\circledR}$ for the adjunctive treatment of symptomatic relief of NP in multiple sclerosis in adults. SATIVEX ${ }^{\circledR}$ contains Tetranabinex ${ }^{\circledR}$ and Nabidiolex ${ }^{\circledR}$ - Cannabis sativa extracts. In this product the principal active components are $2.7 \mathrm{mg}$ of THC and $2.5 \mathrm{mg}$ of CBD.

It is worth emphasizing, that several studies concerning assessment of the Sativex analgesic activity have been carried out [78, 79]. Recently, a doubleblind, randomized, placebo-controlled clinical study showed significant difference between Sativex treatment group and placebo. This product demonstrated the potent analgesic effect and it was generally well tolerated [78]. Other clinical studies largely affirm that NP patients derive benefits from cannabinoid treatment, but evidence to date suggests that abuse on Sativex is likely to occur [79]. This indicates the need to develop new products derived from cannabis extract devoid of THC, therefore further studies should be performed in this field.

\section{Summary}

According to several experimental and review articles [80] currently it can be considered that progress in 
understanding the physiological effects and pharmacological activity of phytocannabinoids may provide new therapeutic opportunities in the treatment of NP. There are some evidences provided both by animal and clinical studies on the efficacy of analgesic effect of different cannabinoids, both hallucinogenic (delta9-tetrahydrocannabinol - THC) and non-hallucinogenic (cannabidiol, delta9-tetrahydrocannabivarin, beta-caryophyllene) compounds. Clinical studies largely affirm that NP patients derive benefits from cannabinoids treatment e.g in peripheral neuropathy, in inflammatory bowel disease, sclerosis multiplex and with cancer pain. It indicates the need to develop a new product derived from cannabis extract that will be devoid of THC, and further studies should be performed in this field. Some aspects of the analgesic and anti-inflammatory effects of Cannabis sativa extracts containing non-psychotropic plant-derived cannabinoids seem to be interesting in context of discovery and development of drugs for the treatment of NP.

\section{Acknowledgements}

\section{Conflict of interest statement}

The authors declare that there is no conflict of interest in the authorship or publication of contribution.

\section{Funding sources}

The research project was financed by the National Centre for Research and Development No. INNOMED/I/11/ NCBR/2014

\section{References}

1. Culter ED, Furukawa KT. Neuropathic pain: treatment options report. California HealthCare Fundation. 2006;1-29.

2. Baron R, Andreas B, Gunnar W. Neuropathic pain: diagnosis, pathophysiological mechanisms, and treatment. Lancet Neurol. 2010;9:807-819.

3. Bouhassira D, Lantéri-Minet M, Attal N, Laurent B, Touboul C. Prevalence of chronic pain with neuropathic characteristics in the general population. Pain. 2008;136:380-387.

4. Lairda B, Colvinb L, Fallona M. Management of cancer pain: basic principles and neuropathic cancer pain. Eur J Cancer. 2008;44:1078-1082.

5. Urch CE, Dickenson AH. Neuropathic pain in cancer. Eur J Cancer. 2008;44:1091-1096.

6. Gondim FAA, Brannagan TH, Sander HW, Chin RL, Latov $N$. Peripheral neuropathy in patients with inflammatory bowel disease. Brain. 2005;128:867-879.

7. Attal N, Cruccu G, Baron R, Haanpa M, Hansson P, Jensen TS, Nurmikko T. EFNS guidelines on the pharmacological treatment of neuropathic pain: 2010 revision. Eur J Neurol. 2010;17:1113-1123.

8. Woroń J, Filipczak-Bryniarska I, Dorazil-Dudzik M, Wordliczek J. Bezpieczeństwo pacjenta w farmakoterapii bólu. Ból. 2009;10(3): 47-72.
9. Yanow J, Pappagallo M, Pillai L. Complex Regional Pain Syndrome (CRPS/RSD) and neuropathic pain: role of intravenous bisphosphonates as analgesics. ScientificWorld Journal. 2008;8:229-236.

10. Authier N, Balayssac D, Marchand F, Ling B, Zangarelli A, Descoeur J, Coudore F, Bourinet E, Eschalier A. Animal Models of Chemotherapy-Evoked Painful Peripheral Neuropathies. Neurotherapeutics 2009;6:620-629.

11. Walker JM, Huang SM. Cannabinoid analgesia. Pharmacol Ther. 2002;95:127-135.

12. Palmer SL, Thakur GA, Makriyannis A. Cannabinergic ligands. Chem Phys Lipids. 2002;121:3-19.

13. Malek N, Kucharczyk M, Starowicz K. Alterations in the Anandamide Metabolism in the Development of Neuropathic Pain. Biomed Res Int. 2014. Article ID 686908.

14. Luchicchi A, Pistis M. Anandamide and 2-arachidonoylglycerol: pharmacological properties, functional features, and emerging specificities of the two major endocannabinoids. Mol Neurobiol. 2012;46:374-392.

15. Sousa-Valente J, Varga K, Ananthan A, Khajuria A, Nagy I. Anandamide in primary sensory neurons: too much of a good thing? Eur J Neurosci. 2014;39:409-418.

16. Desroches J, Charron S, Bouchard JF, Beaulieu P. Endocannabinoids decrease neuropathic pain-related behavior in mice through the activation of one or both peripheral CB1 and CB2 receptors. Neuropharmacol. 2014;77:441-452.

17. Pertwee RG. The Therapeutic Potential of Drugs That Target Cannabinoid Receptors or Modulate the Tissue Levels or Actions of Endocannabinoids. AAPS J. 2005;7:625-654.

18. Salio C, Fischer J, Franzoni MF, Mackie K, Kaneko T, Conrath $\mathrm{M}$. CB1-cannabinoid and mu-opioid receptor colocalization on postsynaptictarget in the rat dorsal horn. Neuroreport. 2001;12:3689-3692.

19. Rodriguez JJ, Mackie K, Pickel VM. Ultrastructural localization of the CB1 cannabinoid receptor in mu-opioid receptor patches of the rat Caudate putamen nucleus. J Neurosci. 2001;21:823-833.

20. Gifford AN, Makriyannis A, Volkow ND. Gatley SJ. In vivo imaging of the brain cannabinoid receptor. Chem Phys Lipids. 2002;121:65-72.

21. Lichtman AH, Cook SA, Martin BR. Investigation of brain sites mediating cannabinoid-induced antinociception in evidence supporting periaqueductal gray involvement. J Pharmacol Exp Ther. 1996;276:585-593.

22. Hohmann AG. Spinal and peripheral mechanisms of cannabinoid antinociception: behavioral, neurophysiological and neuroanatomical perspectives. Chem Phys Lipids. 2002;121:173-190.

23. Vigano D, Rubino T, Parolaro D. Molecular and cellular basis of cannabinoid and opioid interactions. Pharmacol Biochem Behav. 2005;81:360-368.

24. Manzanares J, Corchero J, Romero J, Fernandez-Ruiz JJ, Ramos A, Fuentes JA. Pharmacological and biochemical interactions between opioids and cannabinoids. Trends Pharmacol Sci. 1999;20:287-294.

25. Pertwee RG. Cannabinoid receptors and pain. Prog Neurobiol. 2001;63:569-611.

26. Valenzano KJ, Tafessem L, Lee G, Harrison JE, Bouletm JM, Gottshallm SL. Pharmacological and pharmacokinetic characterization of the cannabinoid receptor 2 agonist, GW405833, utilizing rodent models of acute and chron- 
ic pain, anxiety, ataxia and catalepsy. Neuropharmacol. 2005;48:658-672.

27. Palazzo E, Luongo Lo, de Novellis V, Rossi F, Maione S. The role of cannabinoid receptors in the descending modulation of pain. Pharmaceuticals. 2010;3:2661-2673.

28. Leung L, Cahill CM. TNF-alpha and neuropathic pain a review. J Neuroinflammation. 2010;16:7-27.

29. Moalem G, Tracey DJ. Immune and inflammatory mechanisms in neuropathic pain. Brain Res Rev. 2006;51: 240-264.

30. Machelska H. Dual peripheral actions of immune cells in neuropathic pain. Arch Immunol Ther Exp (Warsz). 2011;59:11-24.

31. Jaggi AS, Singh N. Differential effect of spironolactone in chronic constriction injury and vincristine-induced neuropathic pain NPin rats. Eur J Pharmacol. 2010;648: 102-109.

32. Karin M, Yamamoto Y, Wang QM. The IKK NF-kappa B system: a treasure trove for drug development. Nat Rev Drug Discov. 2004;3:17-26.

33. Yamamoto Y, Gaynor RB. IkappaB kinases: key regulators of the NF-kappaB pathway. Trends Biochem Sci. 2004;29:72-79.

34. Ledeboer A, Gamanos M, Martin D, Maier SF, Watkins $L R$, Quan N. Involvement of spinal cord nuclear factor kappaB activation in rat models of proinflammatory cytokine-mediated pain facilitation. Eur J Neurosci. 2005;22:1977-1986.

35. Kaltschmidt B, Uherek M, Wellmann H, Volk B, Kaltschmidt C. Inhibition of NF-kappaB potentiates amyloid betamediated neuronal apoptosis. Proc Natl Acad Sci USA. 1999;96:9409-9414.

36. Ma W, Bisby MA. Increased activation of nuclear factor kappa $B$ in rat lumbar dorsal root ganglion neurons following partial sciatic nerve injuries. Brain Res. 1998;797:243-254.

37. Mattson MP, Camandola S. NF-kappaB in neuronal plasticity and neurodegenerative disorders. J Clin Invest. 2001;107:247-254.

38. Bethea JR, Castro M, Keane RW, Lee TT, Dietrich WD, Yezierski RP. Traumatic spinal cord injury induces nuclear factor-kappaB activation. J Neurosci. 1998;18: 3251-3260.

39. Niederberger E, Kühlein H, Geisslinger G. Update on the pathobiology of neuropathic pain. Expert Rev Proteomics. 2008;5:799-818.

40. Niederberger E, Geisslinger G. The IKK-NF-\{kappa\}B pathway: a source for novel molecular drug targets in pain therapy? The FASEB Journal. 2008;22:3432-3442.

41. Reuter U, Chiarugi A, Bolay H, Moskowitz MA. Nuclear factor-kappaB as a molecular target for migraine therapy. Ann. Neurol. 2002;51:507-516.

42. Sarchielli P, Floridi A, Mancini ML, Rossi C, Coppola F, Baldi A, Pini LA, Calabresi P. NF-kappaB activity and iNOS expression in monocytes from internal jugular blood of migraine without aura patients during attacks. Cephalalgia. 2006;26:1071-1079.

43. Wu LC, Goettl VM, Madiai F, Hackshaw KV, Hussain SR. Reciprocal regulation of nuclear factor kappa $B$ and its inhibitor ZAS3 after peripheral nerve injury. BMC Neurosci. 2006;7:4.
44. Zhang YP, Fu Es, Sagen J, Levitt RC, Candiotti KA, Bethea JR, Brambilla R. Glial NF-kappa B inhibition alters neuropeptide expression after sciatic nerve injury in mice. Brain Res. 2011;1385:38-46.

45. Fu ES, Zhang YP, Sagen J, Candiotti KA, Morton PD, Liebl DJ, Bethea JR, Brambilla R. Transgenic inhibition of glial NF-kappa B reduces pain behavior and inflammation after peripheral nerve injury. Pain. 2010;148:509-518.

46. Wu LJ, Zhuo M. Targeting the NMDA receptor subunit NR2B for the treatment of neuropathic pain. Neurotherapeutics. 2009;6:693-702.

47. Tian Y, Wang S, Ma Y, Lim G, Kim H, Mao J. Leptin enhances NMDA-induced spinal excitation in rats: A functional link between adipocytokine and neuropathic pain. Pain. 2011;152:1263-1271.

48. Richardson JD, Aanonsen L, Hargreaves KM. Hypoactivity of the spinal cannabinoid system results in NMDA-dependent hyperalgesia. J Neurosci. 1998;8:451-457.

49. Kauppila T. Correlation between autotomy-behavior and current theories of neuropathic pain. Neurosci Biobehav Rev. 1998;23:111-129.

50. Collins S, Sigtermans MJ, Dahan A, Zuurmond WW, Perez RS. NMDA receptor antagonists for the treatment of neuropathic pain. Pain Medicine. 2010;11:1726-1742.

51. Izzo AA, Borrelli F, Capasso R, Di Marzo V, Mechoulam R. Non-psychotropic plant cannabinoids: new therapeutic opportunities from an ancient herb. Cell press. Trends Pharmacol Sci. 2009;30:515-527.

52. Mechoulam R. The pharmacohistory of Cannabis sativa. In: Mechoulam R (ed.). Cannabinoids as therapeutic agents. Boca Raton; CRC; 1986.

53. Razdan RK. Structure activity relationships in cannabinoids. Pharmacol Rev. 1986;38:75-149.

54. Gardner EL. Addictive potential of cannabinoids: the underlying neurobiology. Chem Phys Lipids. 2002;121:267-290.

55. Razdan RK, Mahadevan A. Recent advances in the synthesis of endocannabinoid related ligands. Chem Phys Lipids. 2002;121:21-33.

56. Mechoulam R, Hanus L. Cannabidiol: an overview of some chemical and pharmacological aspects. Part I: chemical aspects. Chem Phys Lipids. 2002;121:35-43.

57. Gertsch J, Pertwee RG, Di Marzo V. Phytocannabinoids beyond the Cannabis plant - do they exist? Br J Pharmacol. 2010;160(3):523-529.

58. Fischedick JT, Hazekamp A, Erkelens T, Choi YH, Verpoorte R. Metabolic fingerprinting of Cannabis sativa L., cannabinoids and terpenoids for chemotaxonomic and drug standardization purposes. Phytochem. 2010;71:2058-2073.

59. Fetterman PS, Keith ES, Waller CW, Guerrero O, Doorenbos NJ, Quimby MW. Mississippi-grown Cannabis sativa L. preliminary observation on chemical definition of phenotype and variations in tetrahydrocannabinol content versus age, sex, and plant part. J Pharm Sci. 1971;60:1246-1277.

60. Thomas A, Stevenson LA, Wease KN, Price MR, Baillie G, Ross RA, Pertwee RG. Evidence that the plant cannabinoid D9-tetrahydrocannabivarin is a cannabinoid CB1 and CB2 receptor antagonist. Br J Pharmacol. 2005;146:917-926. 
61. Bolognini D, Costa B, Maione S, Comelli F, Marini P, Di Marzo V, et al. The plant cannabinoid delta9-tetrahydrocannabivarin can decrease signs of inflammation and inflammatory pain in mice. Br J Pharmacol. 2010;160:677-687.

62. Malan TP, Ibrahim MM, Vanderah TW, Makriyannis A, Porreca F. Inhibition of pain responses by activation of CB2 cannabinoid receptors. Chem Phys Lipids. 2002;121:191-200.

63. Gertsch J, Leonti M, Raduner S, Racz I, Chen JZ, Xie XQ, Altmann KH, Karsak M, Zimmer A. Beta-caryophyllene is a dietary cannabinoid. Proc Natl Acad Sci USA. 2008;105:9099-9104.

64. Bento AF, Marcon R, Dutra RC, Claudino RF, Cola M, Leite DF, Calixto JB. $\beta$-Caryophyllene inhibits dextran sulfate sodium-induced colitis in mice through $C B 2$ receptor activation and PPAR $\gamma$ pathway. Am J Pathol. 2011;178: 1153-1166.

65. Klauke AL, Racz I, Pradier B, Markert A, Zimmera AM, Gertsch J, Zimmer A. The cannabinoidCB2 receptor-selective phytocannabinoidbeta-caryophylleneexerts analgesic effectsinmousemodelsof inflammatory andneuropathicpain. Eur Neuropsychopharmacol. 2014;24:608-620.

66. Zuardi AW, Crippa JAS, Hallak JEC, Moreira FA, Guimarães FS. Cannabidiol, a Cannabis sativa constituent, as an antipsychotic drug. Braz J Med Biol Res. 2006;39:421-429.

67. Campos AC, Guimaraes FS. Involvement of 5HT1A receptors in the anxiolytic-like effects of cannabidiol injected into the dorsolateral periaqueductal gray of rats. Psychopharmacol (Berl). 2008;199:223-230.

68. Evans FJ. Cannabinoids: the separation of central from peripheral effects on a structural basis. Planta Med. 1991;57(Suppl.):60-67.

69. Formukong EA, Evans AT, Evans FJ. Analgesic and anti-inflammatory activity of constituents of Cannabis sativa L. Inflammation. 1988;12:361-371.

70. Sanders J, Jackson DM, Starmer GA. Interactions among the cannabinoids in the antagonism of the abdominal constriction response in the mouse. Psychopharmacol (Berl.) 1979;61:281-285.

71. Costa B, Trovato AE, Comelli F, Giagnoni G, Colleoni M. The non-psychoactive cannabis constituent cannabidiol is an orally effective therapeutic agent in rat chronic inflammatory and neuropathic pain. Eur J Pharmacol. 2007;556:75-83.

72. Costa B, Colleoni M, Conti S, Parolaro D, Franke C, Trovato $A E$, Giagnoni $G$. Oral anti-inflammatory activity of cannabidiol, a non-psychoactive constituent of cannabis, in acute carrageenan-induced inflammation in the rat paw. Naunyn-Schmiedeberg's Arch Pharmacol. 2004;369:294-299.

73. Zurier RB. Prospects for Cannabinoids as Anti-inflammatory Agents. J Cell Biochem. 2003;88:462-466.

74. Weiss L, Zeira M, Reich S, Har-Noy M, Mechoulam R, Slavin S, Gallily R. Cannabidiol lowers incidence of diabetes in non-obese diabetic mice. Autoimmunity. 2006; 39:143-151.

75. Toth CC, Jedrzejewski NM, Ellis CL, Frey WH. Cannabinoid-mediated modulation of neuropathic pain and microglial accumulation in a model of murine type I diabetic peripheral neuropathic pain. Molecular Pain. 2010;6:16.

76. Zajicek JP, Apostu V. Role of cannabinoids in multiple sclerosis. CNS Drugs. 2011;25:187-201.

77. Grotenhermen F. Cannabinoids in cancer pain. Cannabinoids. 2010;5:1-3.

78. Langford RM, Mares J, Novotna A, Vachova M, Novakova I, Notcutt W, Ratcliffe S. A double-blind, randomized, placebo-controlled, parallel-group study of THC/CBD oromucosal spray in combination with the existing treatment regimen, in the relief of central neuropathic pain in patients with multiple sclerosis. J Neurol. 2013;260:984-997.

79. Robson P. Abuse potential and psychoactive effects of $\delta$-9-tetrahydrocannabinol and cannabidiol oromucosal spray (Sativex), a new cannabinoid medicine. Expert Opin Drug Saf. 2011;10:675-685.

80. Fine PG, Rosenfeld MJ. Cannabinoids for neuropathic pain. Curr Pain Headache Rep. 2014;18:451.

Acceptance for editing: 2014-12-10 Acceptance for publication: 2014-12-31

\section{Correspondence address:} Marcin Ożarowski Department of Pharmaceutical Botany and Plant Biotechnology Poznan University of Medical Sciences 14 Św. Marii Magdaleny Street, 61-861 Poznań, Poland phone: +48616687847 fax: +48616687861 email: mozarow@ump.edu.pl 